\title{
A modified immunofluorescence in situ hybridization method to detect long non-coding RNAs and proteins in frozen spinal cord sections
}

\author{
CHONG MENG ${ }^{1-3}, \mathrm{XIN} Z \mathrm{ZHOO}^{1-3}$ and JIE LAO ${ }^{1-3}$ \\ ${ }^{1}$ Department of Hand Surgery, Huashan Hospital, Fudan University, Shanghai 200040; \\ ${ }^{2}$ Key Laboratory of Hand Reconstruction, Ministry of Health; ${ }^{3}$ Shanghai Key Laboratory of \\ Peripheral Nerve and Microsurgery, Fudan University, Shanghai 200032, P.R. China
}

Received July 29, 2016; Accepted May 5, 2017

DOI: $10.3892 /$ etm.2018.6046

\begin{abstract}
Immunofluorescence in situ hybridization (immuno-FISH) is widely used to co-detect RNAs and proteins in order to study their spatial distribution in cells. The present study used a modified immuno-FISH protocol for the detection of long non-coding RNAs (lncRNAs) and proteins in frozen spinal cord sections. The spinal cords of Sprague-Dawley rats were harvested, frozen and sectioned $(10 \mu \mathrm{m})$, and oligonucleotide probes and antibodies were prepared. Following antigen retrieval, dehydration, prehybridization, hybridization, post-hybridization and immunofluorescence staining, images were captured. Antigen retrieval was performed by autoclaving or proteinase $\mathrm{K}$ treatment, and their effects on the hybridization signal were compared. The same sections were successfully stained by immunofluorescence. Satisfactory fluorescent signals of lncRNA and protein were obtained. The results of the present study suggest that the modified protocol of immuno-FISH for the detection of IncRNAs and proteins in frozen spinal cord sections is effective and time-efficient, and the required reagents are readily available.
\end{abstract}

\section{Introduction}

A number of long non-coding RNAs (lncRNAs) have been identified in the past decade, and previous results link specific lncRNAs to many physiological processes and to various diseases, including cancer and chronic pain (1-3). Investigation into the tissue and subcellular localization of lncRNAs is necessary to determine their function and underlying mechanisms. Metastasis-associated lung adenocarcinoma transcript 1 (MALAT1) is an abundant, ubiquitously expressed lncRNA (4).

Correspondence to: Professor Jie Lao, Department of Hand Surgery, Huashan Hospital, Fudan University, 12 Middle Wulumuqi Road, Jing'an, Shanghai 200040, P.R. China

E-mail: laojie633@sina.com

Key words: fluorescent in situ hybridization, immunofluorescence, long non-coding RNA, frozen section, antigen retrieval
It has previously been reported that MALAT1 is expressed in the nervous system and regulates lung cancer and glioma (4-6).

In situ hybridization (ISH) is a useful tool for the quantification and localization of specific RNAs within cultured cells or tissue sections. In ISH, an oligonucleotide probe is used to detect the RNA of interest through complementary base pairing (7). Historically, ISH was performed with radioactive probes; however, the handling of radioactive materials has many risks, and the method of image capture was time consuming with this technique (7). These disadvantages were overcome with the advent of fluorescence in situ hybridization (FISH), which uses fluorescently labeled probes. The utility of FISH is increased when it is combined with other techniques; for example, immunofluorescence in situ hybridization (immuno-FISH) is a combination of FISH and immunohistochemistry that enables the detection of RNAs and proteins in the same samples (8). Variations of the immuno-FISH method have previously been documented. Nehmé et al (9) reported that treatment with proteinase $\mathrm{K}(\mathrm{PK})$ increased the sensitivity of FISH, but decreased the signal of immunofluorescence staining in a study of $65-\mathrm{kDa}$ glutamic acid decarboxylase mRNA and three proteins [neuronal nuclei $(\mathrm{NeuN}), \mathrm{FBJ}$ murine osteosarcoma viral oncogene homolog B and tyrosine hydroxylase] in frozen brain sections. Although the author provided a method to correct this problem (9), the method was complicated and its application in studies of noncoding RNA has not been validated. de Planell-Saguer et al (10) reported an immuno-FISH method for detecting non-coding RNAs in paraffin-embedded tissues and cultured cells; however, they did not report its application in frozen tissue sections.

In the present study, a modified immuno-FISH protocol was used to investigate the expression and distribution of lncRNA MALAT1 and its association with the protein markers of neurons, microglia and astrocytes in $10-\mu \mathrm{m}$ frozen spinal cord slices from rats. The modified protocol was also compared with other reported protocols.

\section{Materials and methods}

Animals. Adult male Sprague Dawley rats $(\mathrm{n}=6,200-250 \mathrm{~g}$, 6-7 weeks old; Shanghai SLAC Laboratory Animal Co., Ltd., 
Shanghai, China) were housed under a 12-h light/dark cycle, at $23-25^{\circ} \mathrm{C}$ and $45-50 \%$ humidity and provided with free access to food and water. All surgical and experimental procedures were approved by the Animal Ethics Committee of Fudan University (Shanghai, China).

Reagents. To prepare a $1 \%$ sodium pentobarbital solution, $5 \mathrm{~g}$ sodium pentobarbital (cat. no. 69020181; Sinopharm Chemical Reagent Co., Ltd., Shanghai, China) was dissolved in $500 \mathrm{ml}$ distilled (d) $\mathrm{H}_{2} \mathrm{O}$, and the solution was stored at $4^{\circ} \mathrm{C}$ in the dark. To prepare 11 of $4 \%$ paraformaldehyde, $40 \mathrm{~g}$ paraformaldehyde was added to 11 of $1 \mathrm{X}$ phosphate-buffered saline (PBS) and heated gradually to $60^{\circ} \mathrm{C}$ with continuous stirring to dissolve the paraformaldehyde. The $\mathrm{pH}$ was subsequently adjusted to 7.4 with $\mathrm{NaOH}$. To prepare a 10 or $30 \%$ sucrose solution, 10 or 30 g sucrose (cat. no. 10021418; Sinopharm Chemical

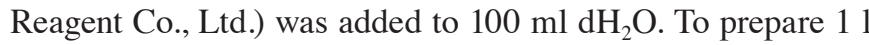
of antigen unmasking buffer ( $10 \mathrm{mM}$ sodium citrate), $2.94 \mathrm{~g}$ sodium citrate tribasic salt dihydrate $\left(\mathrm{C}_{6} \mathrm{H}_{5} \mathrm{Na}_{3} \mathrm{O}_{7} \cdot 2 \mathrm{H}_{2} \mathrm{O}\right.$, cat. no. 10019418; Sinopharm Chemical Reagent Co., Ltd.) was added to $11 \mathrm{dH}_{2} \mathrm{O}$. The $\mathrm{pH}$ was adjusted to 6.0 and the solution was subsequently filtered (pore diameter, $75 \mu \mathrm{m}$ ). To prepare 11 of 20X saline-sodium citrate (SSC), $175.2 \mathrm{~g}$ $\mathrm{NaCl}$ and $88.2 \mathrm{~g}$ sodium citrate tribasic salt dihydrate were

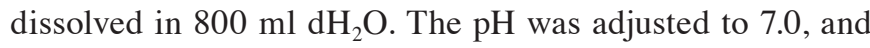
$\mathrm{dH}_{2} \mathrm{O}$ was added to bring the volume to 11 . To prepare $100 \mathrm{ml}$ of prehybridization buffer, $3 \mathrm{~g}$ bovine serum albumin (BSA; cat. no. 69003433; Sinopharm Chemical Reagent Co., Ltd.) was added to $100 \mathrm{ml}$ of $4 \mathrm{X}$ SSC. The resulting solution was used to prepare $0.1,1,2$ and $4 \mathrm{X}$ SSC. To prepare $10 \mathrm{ml}$ of hybridization buffer, $1 \mathrm{~g}$ dextran sulfate (cat. no. S14047; Shanghai Yuanye Biotechnology Co., Ltd., Shanghai, China) and $1 \mathrm{ml}$ deionized formamide (cat. no. 30091218; Sinopharm Chemical Reagent Co., Ltd.) were added to $9 \mathrm{ml}$ of $4 \mathrm{X}$ SSC. To prepare $100 \mathrm{ml}$ of blocking buffer, $1 \mathrm{~g}$ BSA and $0.1 \mathrm{ml}$ Tween-20 were added to $100 \mathrm{ml}$ of $1 \mathrm{X}$ PBS. To prepare $50 \mathrm{ml}$ of 4',6-diamidino-2-phenylindole (DAPI) staining solution, $0.5 \mu 1$ DAPI stock solution was diluted in $50 \mathrm{ml}$ of $1 \mathrm{X}$ PBS.

Riboprobes and antibodies. All DNA oligonucleotides, including three probes for rat lncRNA malat1 (Malat1-a, -b and -c) and one probe for GAPDH (positive control; Table I), were designed and synthesized and labeled on the 5'-end with Alexa Fluor 633 by Invitrogen (Thermo Fisher Scientific, Inc. Waltham, MA, USA). Probes were stored at $-20^{\circ} \mathrm{C}$ in powder form. To prepare a $250 \mathrm{nM}$ working solution, probes were diluted in hybridization buffer. Antibodies against NeuN, Iba1 and GFAP were used as biomarkers of neurons, microglia and astrocytes, respectively (11). The primary and Alexa Fluor 488-conjugated secondary antibodies used for immunofluorescence were purchased from Abcam (Cambridge, MA, USA; Table II) and diluted with blocking buffer to 1:500 and 1:400, respectively.

Tissue preparation. Rats were anesthetized with an intraperitoneal injection of $1 \%$ sodium pentobarbital solution $(40 \mathrm{mg} / \mathrm{kg})$ and transcardially perfused with $1 \mathrm{X}$ PBS and $500 \mathrm{ml}$ of $4 \%$ paraformaldehyde in phosphate buffer $(0.1 \mathrm{M}, \mathrm{pH}$ 7.4). The spinal cord was harvested at the cervical level and specimens were immersed in $4 \%$ paraformaldehyde for $4 \mathrm{~h}$ at $4^{\circ} \mathrm{C}$. The tissues were then sequentially immersed in 10 and $30 \%$ sucrose until the spinal cords fell to the bottom. Spinal cords were embedded in optimal cutting temperature compound (cat. no. 4583; Sakura Finetek USA, Inc., Torrance, CA, USA) and mounted on a microtome stage. Horizontal sections $(10 \mu \mathrm{m})$ were mounted onto pre-warmed poly-l-lysine-coated slides (cat. no. P4981; Thermo Fisher Scientific, Inc.).

Antigen retrieval and dehydration. Following desiccation for $20 \mathrm{~min}$ at room temperature, slides were rinsed twice with 1X SSC (5 min/wash). The slides were placed into a Coplin jar filled with antigen unmasking buffer, which was placed into an autoclave and heated to $100^{\circ} \mathrm{C}$ for $5 \mathrm{~min}$ and subsequently cooled to room temperature. Sections were then washed three times with 1X SSC (5 min/wash). The tissue sections were dehydrated in a graded series of ethanol (50, 70, 90 and 100\%; $3 \mathrm{~min}$ each) and air-dried for $10 \mathrm{~min}$.

For comparison, some slides were treated with PK instead of treatment with antigen unmasking buffer and autoclaving, according to the method described by Nehmé et al (9). For this method, the slides were immersed in a buffer containing $0.1 \mathrm{M}$ Tris-HCl (pH 8), $50 \mathrm{mM}$ EDTA (pH 8) and $10 \mu \mathrm{g} / \mathrm{ml} \mathrm{PK}$ (Roche Diagnostics, Basel, Switzerland) for $25 \mathrm{~min}$ at $37^{\circ} \mathrm{C}$.

Prehybridization. The prehybridization buffer was warmed to $\sim 47^{\circ} \mathrm{C}$ [usually $22-25^{\circ} \mathrm{C}$ below the melting temperature $\left(\mathrm{T}_{\mathrm{m}}\right)$ of probes] and $200 \mu \mathrm{l}$ warmed prehybridization buffer was pipetted onto each slide and prehybridized for $20 \mathrm{~min}$ in a humid chamber $\left(47^{\circ} \mathrm{C}\right)$. The probes (Malat1-a, -b and $-\mathrm{c}$ and GAPDH) were diluted with hybridization buffer and denatured at $65^{\circ} \mathrm{C}$ for $10 \mathrm{~min}$, then stored on ice.

Hybridization. The prehybridization buffer was removed and $100 \mu \mathrm{l}$ aliquots of each probe (or same volume of hybridization buffer without probes as negative control) were added to separate slides and hybridized overnight (4-16 h) at the same temperature used in the prehybridization step. From this step on, all slides were kept in the dark.

Post-hybridization. Following hybridization, the slides were rinsed with the following solutions: $4 \mathrm{X}$ SSC (twice at $5 \mathrm{~min} /$ wash), $2 \mathrm{X} \mathrm{SSC}$ (5 min), $1 \mathrm{X} \mathrm{SSC} \mathrm{(5} \mathrm{min),} \mathrm{and} \mathrm{0.1X} \mathrm{SSC}$ (5 min) at the same temperature as in the hybridization step. The slides were then rinsed with $1 \mathrm{X}$ PBS for $5 \mathrm{~min}$ at room temperature.

Immunofluorescence staining. Following in situ hybridization, the sections were blocked in blocking buffer for $30 \mathrm{~min}$ at $37^{\circ} \mathrm{C}$. From this step on, sections were kept in a humid chamber to protect the tissue sections from drying out. The blocking buffer was removed and $200 \mu \mathrm{l}$ primary antibody diluted in blocking buffer was added (Table II), and the sections were incubated overnight at $4^{\circ} \mathrm{C}$ in a humid chamber. Sections were rinsed three times with $1 \mathrm{X}$ PBS (5 min/wash), then incubated with corresponding secondary antibody (200 $\mu$ l diluted in blocking buffer) for $2 \mathrm{~h}$ at $37^{\circ} \mathrm{C}$. Slides were subsequently rinsed three times with $1 \mathrm{X}$ PBS (5 min/wash). At this point, all FISH and immunofluorescence staining steps were complete. However, if the nucleus needed to be observed, nuclear staining with DAPI was performed. Finally, a few drops of antifade (cat. no. P36965; 
Table I. Riboprobes used in the present study.

\begin{tabular}{|c|c|c|c|c|}
\hline Name & $\mathrm{T}_{\mathrm{m}},{ }^{\circ} \mathrm{C}$ & Sequence, $5^{\prime}-3^{\prime}$ & Length, bp & $\mathrm{GC}, \%$ \\
\hline Malat1-a & 66.1 & GGGCCGTTATAAGAGTCGACTGTCGCATGTACGAAGGCATGAG & 43 & 53.5 \\
\hline Malat1-b & 66.1 & GCGGTTCGTTGGAGGAAGCTAGGAAGAAGGAGCCGAAATGATG & 43 & 53.5 \\
\hline Malat1-c & 62.4 & GGCTGGTAGTTTATTCTTTTCCСССТСССTTAACAAGACTTG & 42 & 45.2 \\
\hline GAPDH & 64.0 & CTTGTGACAAAGTGGACATTGTTGCCATCAACGACCCCTTCATTG & 45 & 46.7 \\
\hline
\end{tabular}

Malat, metastasis-associated lung adenocarcinoma transcript; $\mathrm{T}_{\mathrm{m}}$, melting temperature; bp, base pairs.

Table II. Antibodies used in the present study.

\begin{tabular}{|c|c|c|c|c|c|c|}
\hline Name & Primary/secondary & Company & Cat. no. & Conjugated & Host & Dilution \\
\hline Anti-NeuN & Primary & Abcam & Ab177487 & No & Rabbit & $1: 500$ \\
\hline Anti-Iba-1 & Primary & Abcam & Ab5076 & No & Goat & $1: 500$ \\
\hline Anti-GFAP & Primary & Abcam & $\mathrm{Ab} 7260$ & No & Rabbit & $1: 500$ \\
\hline Anti-rabbit IgG & Secondary & Abcam & Ab150129 & Alexa fluor 488 & Donkey & $1: 400$ \\
\hline Anti-goat IgG & Secondary & Abcam & Ab150073 & Alexa fluor 488 & Donkey & $1: 400$ \\
\hline
\end{tabular}

NeuN, neuronal nuclei; Iba-1, ionized calcium binding adaptor molecule 1; GFAP, glial fibrillary acidic protein; IgG, immunoglobulin G.

Thermo Fisher Scientific, Inc.) were added to the slides and a coverslip was placed. The slides were sealed with nail polish.

Image acquisition and analysis. Images were captured with a confocal laser-scanning microscope (FluoView ${ }^{\mathrm{TM}}$ FV1000; Olympus Corporation, Tokyo, Japan) equipped with a digital camera and image analysis system (FV10-ASW 4.0; Olympus Corporation). All images were analyzed using Image J 1.44 (National Institutes of Health, Bethesda, MD, USA). Brightness and contrast were adjusted. Positive cells and the background surrounding positive cells were selected as regions of interest. The ratio of integral optical density (IOD) between the positive cells and background signal was calculated using Image J 1.44. All statistical analyses using Student's t-test and histograms were completed with GraphPad Prism 5 (GraphPad Software, Inc., La Jolla, CA, USA). $\mathrm{P}<0.05$ was considered to indicate a statistically significant difference.

\section{Results}

All three probes are effective for immuno-FISH. Satisfactory fluorescent signals were obtained from all three malatl probes (Malat1-a, -b and -c; Fig. 1A-C). During FISH, GAPDH served as a positive control and sections without probes (hybridization buffer only) served as negative controls (Fig. 1D and E). The IOD ratio of Malat1-a, -b, -c group was respectively compared with negative control using Student's t-test. All three Malat1 probes were demonstrated to be effective $(\mathrm{n}=6, \mathrm{P}<0.05)$; however, the Malat1-b probe exhibited the highest signal amplitude (Fig. 1F). Therefore, Malat1-b was used for subsequent experiments.

Antigen retrieval by autoclaving and $P K$ treatment has similar effects on FISH. Two antigen retrieval methods, autoclaving and PK treatment, were compared. Using the same imaging parameters, both methods achieved notable FISH signals (Fig. 2). The IOD ratio of positive cells to background signal was calculated for each group, and did not differ significantly between the two groups (Fig. 2C).

Modified immuno-FISH is effective. The Malat1-b probe was used to detect the expression of malat1 (Fig. 3; labeled red). Using immuno-FISH, malat1 and three different proteins were successfully co-detected. NeuN-positive cells were double labeled with malat1 (green-red merge; Fig. 3A), while cells positive for glial fibrillary acidic protein and ionized calcium binding adaptor molecule 1 (Iba-1) were a single color (green; Fig. 3B and C). These results indicated that Malat1 is expressed in neurons but not in microglia or astrocytes.

\section{Discussion}

Immuno-FISH is a reliable method for the double staining of RNA and cellular proteins (10). It is typically used to detect the localization and abundance of target RNA expression at the histological level (9). LncRNAs are among the most abundant classes of non-coding RNAs (12). Many lncRNAs have been implicated in the functioning of the nervous system and development of disease (13). In the present study, a modified protocol of immuno-FISH was developed. Using this protocol, high-quality fluorescent signals and histological data were obtained that provided information about the expression and distribution of lncRNA malatl and three different proteins in the spinal cord.

Pretreatment of tissue sections is a critical step for obtaining satisfactory fluorescence signals, and this step is modified in different protocols. The purpose of pretreatment is to ensure 


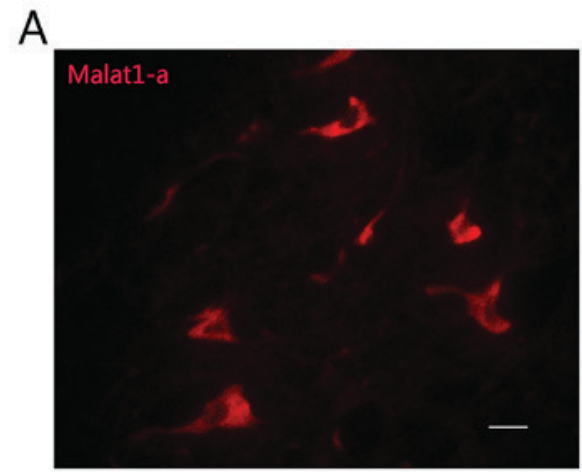

D

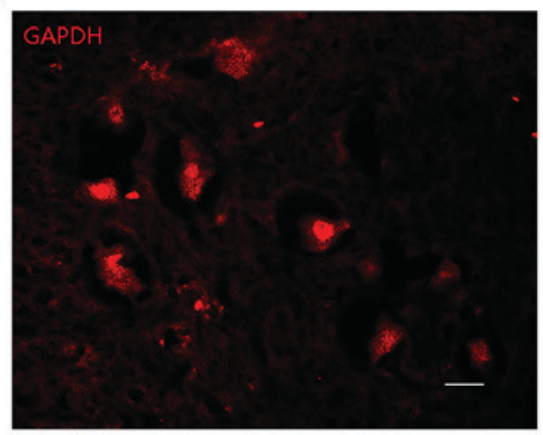

B

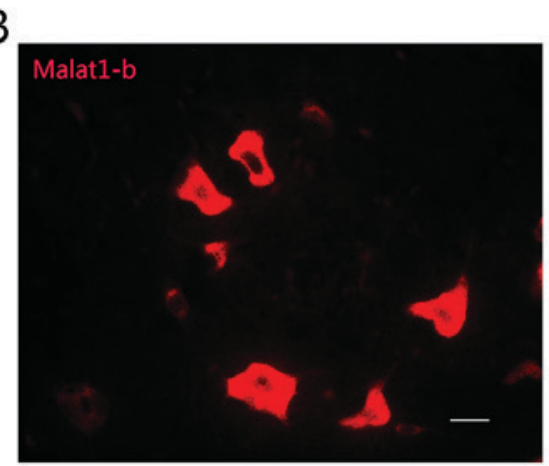

$\mathrm{E}$

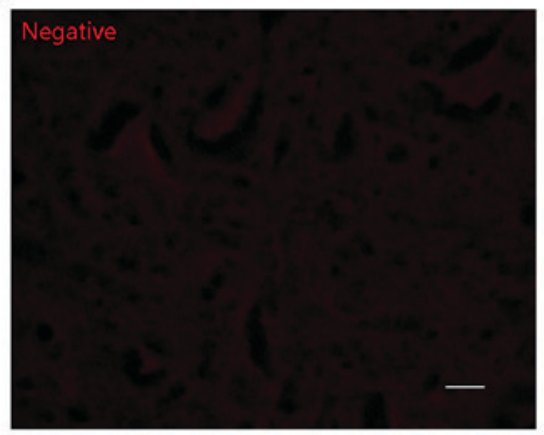

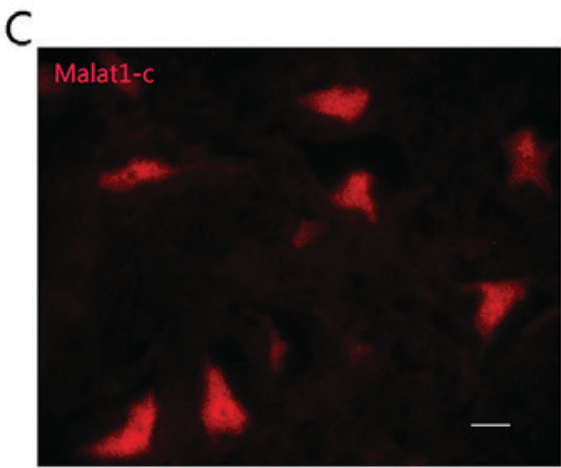

$\mathrm{F}$

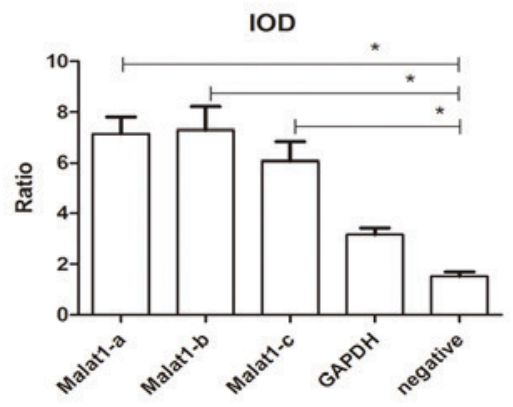

Figure 1. FISH with four probes (Malat1-a, -b and -c and GAPDH) and a negative control (buffer only). Representative images of the (A) Malat1-a, (B) Malat1-b and (C) Malart1-c probes. Representative images of the (D) GAPDH (positive) and (E) negative controls. (F) Mean IOD ratio of each group. Scale bar, $20 \mu \mathrm{m}$; magnification, $\mathrm{x} 100$. Data are presented as the mean \pm standard deviation. ${ }^{*} \mathrm{P}<0.05$ as indicated. FISH, fluorescence in situ hybridization; Malat, metastasis-associated lung adenocarcinoma transcript; IOD, integrated optical density.

A

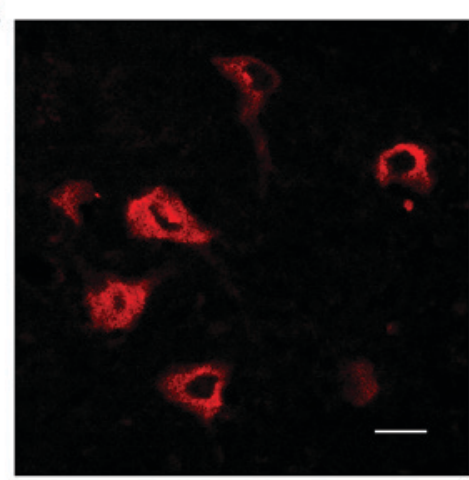

B

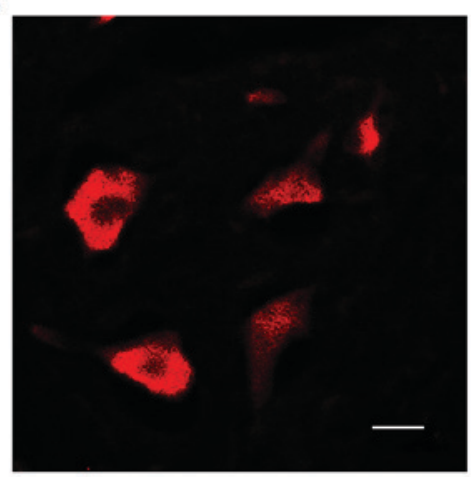

C

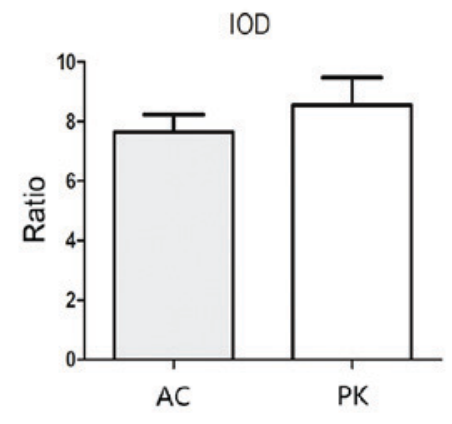

Figure 2. Comparison between autoclaving and PK treatment for antigen retrieval. Representative sections that underwent antigen retrieval by (A) autoclaving and (B) PK treatment. (C) Mean IOD ratio of each group. Scale bar, $20 \mu \mathrm{m}$; magnification, $\mathrm{x} 400$. Data are presented as the mean \pm standard deviation. PK, proteinase $\mathrm{K}$; IOD, integrated optical density; AC, autoclaving.

signal specificity and minimize non-specific background signals (14,15). Acetylation, which negatively charges sections to reduce the adsorption of negatively-charged probes, is widely used as a pretreatment step to reduce background staining $(10,16,17)$. However, in some protocols, acetylation has been reported as a dispensable step $(10,18)$. As such, in the present study, sections were not treated with acetylation, which simplified the protocol and saved time.

In traditional RNA FISH procedures, PK treatment may be used to improve sensitivity, as it denatures many proteins in the membrane and within RNA-protein complexes, making it easier for the probe to cross membranes and bind to target RNA (9). However, previous results have indicated that PK may also denature proteins of interest, which makes it incompatible with immunofluorescence (9). In the present study, sodium citrate-based antigen unmasking and autoclaving were used for antigen retrieval, and high-quality FISH and immunofluorescence signals were obtained. High temperatures may also denature membrane proteins and RNA-protein complexes, unmasking the antigenic sites of target proteins and thus improving antibody-antigen reactions (19). In addition, high pressure prevents solutions from boiling, which otherwise causes tissue sections to peel away from slides.

The reagents used in the current protocol were readily available, relatively non-toxic and inexpensive. Researchers may prepare the antigen unmasking, prehybridization, and 

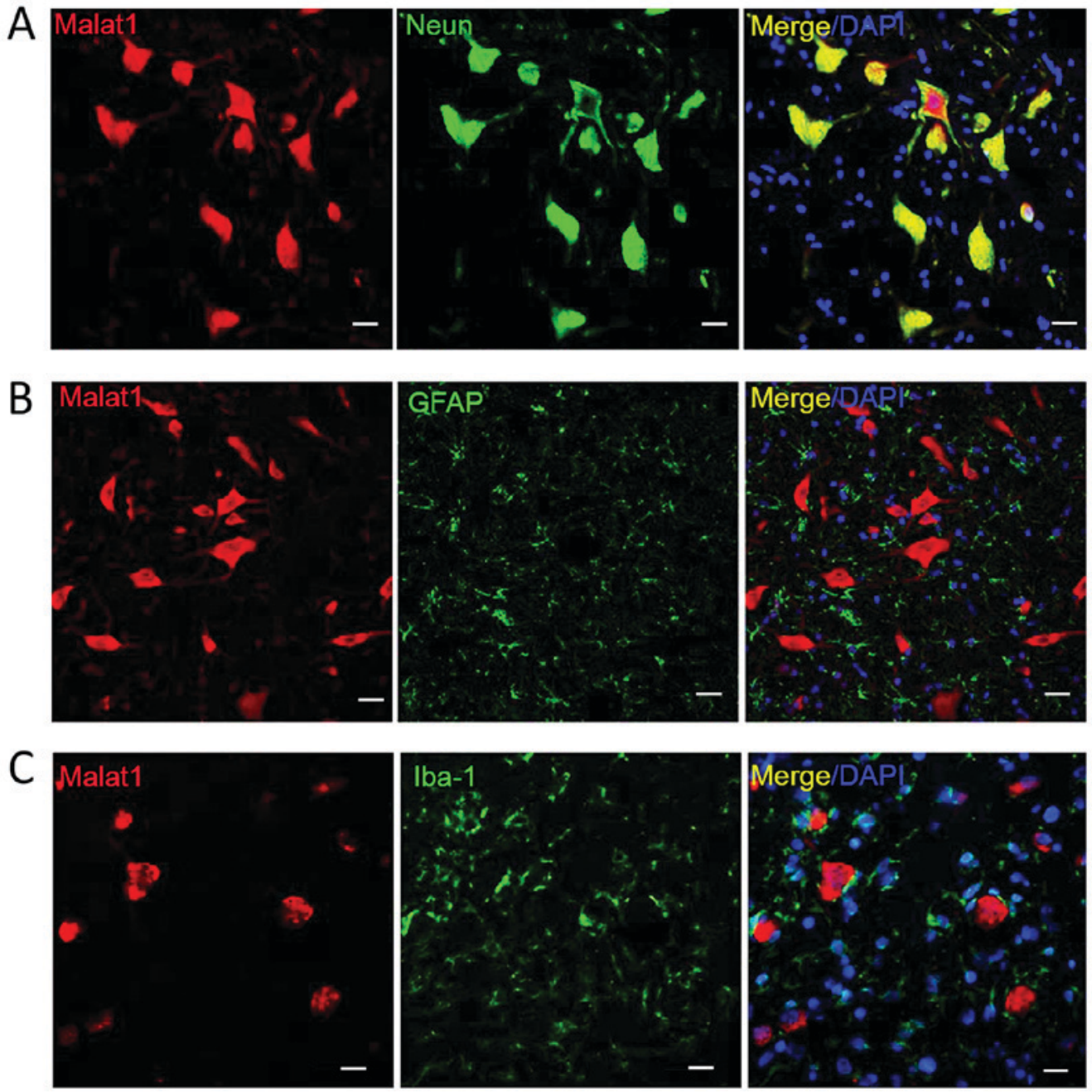

Figure 3. Double labeling for Malat1 and protein markers. Co-detection of Malat1 with (A) NeuN, (B) GFAP and (C) Iba-1. Only NeuN-positive cells were double labeled. Scale bar, $20 \mu \mathrm{m}$, magnification, x100. Malat, metastasis-associated lung adenocarcinoma transcript; NeuN, neuronal nuclei; GFAP, glial fibrillary acidic protein; Iba-1, ionized calcium binding adaptor molecule 1; DAPI, 4',6-diamidino-2-phenylindole.

hybridization buffers using common reagents following the simple formulas listed above. Other reported hybridization buffer solutions include lauroyl sarcosine (18), Denhardt's solution, transfer RNA or dithiothreitol (9), though these may be difficult to obtain and/or store.

Another advantage of the current protocol was that it was time-efficient. All of the steps undertaken in the present study were performed within 24-32 $\mathrm{h}$. The variation in the time required to complete the protocol was mainly due to the antibodies used for immunofluorescence, as different antigen-antibody reactions required different incubation periods. For instance, it was possible to label NeuN in $2 \mathrm{~h}$, whereas Iba- 1 required $>6 \mathrm{~h}$ at $4^{\circ} \mathrm{C}$. Thus, an overnight reaction at $4^{\circ} \mathrm{C}$ is preferred in the majority of immunohistochemistry procedures $(3,9,20)$. In instances where the protocol is applied using other antibodies and the antibody-antigen reaction is not satisfactory, longer reaction times at $4^{\circ} \mathrm{C}$ should be considered.

Malat1 is an abundant lncRNA that has been demonstrated to regulate the progression of many diseases (4). In the present study, the distribution of malat 1 in the spinal cord of rats was assessed using a simple immuno-FISH protocol, and it was demonstrated that malat1 was expressed in neurons but not in microglia or astrocytes. Despite the lack of a signal amplification method, satisfactory fluorescence signals were obtained. However, the abundance of some lncRNAs is low, for example BACE1-AS and lnc-DC $(21,22)$, and in these cases signal amplification treatments, including tyramide amplification and specially designed riboprobes, may be necessary to obtain detectable fluorescence.

In conclusion, the present study performed a simple immuno-FISH protocol for the detection of malat1 lncRNA and protein markers of neurons, microglia and astrocytes in frozen spinal cord sections of rats. Advantages of the modified immune-FISH protocol include the ready availability of reagents and general speed of the method. This protocol may be adapted for other tissues and RNAs, and may also be used for FISH or immunofluorescence alone.

\section{Acknowledgements}

The present study was supported by the Ministry of Science and Technology of China (973 Program; grant no. 2014CB542204 to Yun Wang) and the Science and Technology Commission of Shanghai Municipality (grant no. 16ZR1404200 to Yuzhou Liu). 


\section{References}

1. Gupta RA, Shah N, Wang KC, Kim J, Horlings HM, Wong DJ, Tsai MC, Hung T, Argani P, Rinn JL, et al: Long non-coding RNA HOTAIR reprograms chromatin state to promote cancer metastasis. Nature 464: 1071-1076, 2010.

2. Lee JT: Epigenetic regulation by long noncoding RNAs. Science 338: 1435-1439, 2012.

3. Zhao X, Tang Z, Zhang H, Atianjoh FE, Zhao JY, Liang L, Wang W, Guan X, Kao SC, Tiwari V, et al: A long noncoding RNA contributes to neuropathic pain by silencing Kcna2 in primary afferent neurons. Nat Neurosci 16: 1024-1031, 2013.

4. Gutschner T, Hammerle M and Diederichs S: MALAT1-a paradigm for long noncoding RNA function in cancer. J Mol Med (Berl) 91: 791-801, 2013.

5. Kryger R, Fan L, Wilce PA and Jaquet V: MALAT-1, a non protein-coding RNA is upregulated in the cerebellum, hippocampus and brain stem of human alcoholics. Alcohol 46 629-634, 2012.

6. Han Y, Wu Z, Wu T, Huang Y, Cheng Z, Li X, Sun T, Xie X, Zhou Y and Du Z: Tumor-suppressive function of long noncoding RNA MALAT1 in glioma cells by downregulation of MMP2 and inactivation of ERK/MAPK signaling. Cell Death Dis 7: e2123, 2016.

7. Pardue ML and Gall JG: Molecular hybridization of radioactive DNA to the DNA of cytological preparations. Proc Natl Acad Sci USA 64: 600-604, 1969.

8. Fuller CE and Perry A: Fluorescence in situ hybridization (FISH) in diagnostic and investigative neuropathology. Brain Pathol 12: 67-86, 2002.

9. Nehmé B, Henry M and Mouginot D: Combined fluorescent in situ hybridization and immunofluorescence: Limiting factors and a substitution strategy for slide-mounted tissue sections. J Neurosci Methods 196: 281-288, 2011.

10. de Planell-Saguer M, Rodicio MC and Mourelatos Z: Rapid in situ codetection of noncoding RNAs and proteins in cells and formalin-fixed paraffin-embedded tissue sections without protease treatment. Nat Protoc 5: 1061-1073, 2010.

11. Meng X, Yang F, Ouyang T, Liu B, Wu C and Jiang W: Specific gene expression in mouse cortical astrocytes is mediated by a $1740 \mathrm{bp}-$ GFAP promoter-driven combined adeno-associated virus 2/5/7/8/9. Neurosci Lett 593: 45-50, 2015.

12. Clark MB and Mattick JS: Long noncoding RNAs in cell biology. Semin Cell Dev Biol 22: 366-376, 2011.
13. Qureshi IA, Mattick JS and Mehler MF: Long non-coding RNAs in nervous system function and disease. Brain Res 1338: 20-35, 2010.

14. Namekawa SH and Lee JT: Detection of nascent RNA, single-copy DNA and protein localization by immunoFISH in mouse germ cells and preimplantation embryos. Nat Protoc 6: 270-284, 2011

15. Sui QQ, Zhu J, Li X, Knight GE, He C, Burnstock G, Yuan H and Xiang Z: A modified protocol for the detection of three different mRNAs with a new-generation in situ hybridization chain reaction on frozen sections. J Mol Histol 47: 511-529, 2016.

16. Just L, Timmer M, Tinius J, Stahl F, Deiwick A, Nikkhah G and Bader A: Identification of human cells in brain xenografts and in neural co-cultures of rat by in situ hybridisation with Alu probe. J Neurosci Methods 126: 69-77, 2003.

17. Silahtaroglu AN, Nolting D, Dyrskjøt L, Berezikov E, Møller M, Tommerup N and Kauppinen S: Detection of microRNAs in frozen tissue sections by fluorescence in situ hybridization using locked nucleic acid probes and tyramide signal amplification. Nat Protoc 2: 2520-2528, 2007.

18. Urbanek MO and Krzyzosiak WJ: RNA FISH for detecting expanded repeats in human diseases. Methods 98: 115-123, 2016.

19. White AK, Hansen-Lardy L, Brodersen BW, Kelling CL, Hesse RA and Duhamel GE: Enhanced immunohistochemical detection of infectious agents in formalin-fixed, paraffin-embedded tissues following heat-mediated antigen retrieval. J Vet Diagn Invest 10: 214-217, 1998.

20. Vicuña L, Strochlic DE, Latremoliere A, Bali KK, Simonetti M, Husainie D, Prokosch S, Riva P, Griffin RS, Njoo C, et al: The serine protease inhibitor Serpin A3N attenuates neuropathic pain by inhibiting $\mathrm{T}$ cell-derived leukocyte elastase. Nat Med 21: 518-523, 2015.

21. Wang P, Xue Y, Han Y, Lin L, Wu C, Xu S, Jiang Z, Xu J, Liu Q and Cao X: The STAT3-binding long noncoding RNA lnc-DC controls human dendritic cell differentiation. Science 344 310-313, 2014.

22. Faghihi MA, Modarresi F, Khalil AM, Wood DE, Sahagan BG, Morgan TE, Finch CE, St Laurent G III, Kenny PJ and Wahlestedt C: Expression of a noncoding RNA is elevated in Alzheimer's disease and drives rapid feed-forward regulation of beta-secretase. Nat Med 14: 723-730, 2008.

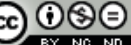

This work is licensed under a Creative Commons Attribution-NonCommercial-NoDerivatives 4.0 International (CC BY-NC-ND 4.0) License. 